\title{
The Implementation of Common European Framework of References (CEFR): What Are the Effects Towards LINUS Students' Achievements?
}

\author{
Wan Illina Wan Ishak, Maslawati Mohamad \\ Sekolah Kebangsaan Kedawang, Langkawi, Kedah Darul Aman, Faculty of Education, National University of Malaysia, \\ Bangi, Malaysia \\ Email: exodus1287@gamil.com
}

How to cite this paper: Ishak, W. I. W., \& Mohamad, M. (2018). The Implementation of Common European Framework of References (CEFR): What Are the Effects Towards LINUS Students' Achievements? Creative Education, 9, 2714-2731. https://doi.org/10.4236/ce.2018.916205

Received: September 17, 2018 Accepted: December 9, 2018

Published: December 12, 2018

Copyright $\odot 2018$ by authors and Scientific Research Publishing Inc. This work is licensed under the Creative Commons Attribution International License (CC BY 4.0).

http://creativecommons.org/licenses/by/4.0/ (c) (i) Open Access

\begin{abstract}
Realizing the importance of English language, Malaysian government has implemented numerous programs to boost English language standard among younger generations. One of the remedial intervention programs for primary schools is called the Literacy and Numeracy Screening or LINUS. LINUS program refers to a set of screening tests which are conducted every year to identify students' weaknesses in literacy skills specifically in reading and writing. It was introduced in 2010 which aims at enhancing the rate of English literacy among primary school learners. Recently, another new curriculum known as Common European Framework of Resources or CEFR has been introduced. CEFR that adopted the English way of learning culture seems to raise many issues among English language teachers. It is important for educators to carry out a study in order to obtain more information on to what extent these two programs help to improve English language standard among primary students. Thus, this study was conducted to identify the effects of CEFR towards the achievement of Year 2 students from 3 LINUS classes in a suburban primary school in Langkawi, Kedah, Malaysia. Data analysis has been made by comparing the data taken from the second screening results of LINUS in 2017 with the data from the first screening result of LINUS in early 2018 . The findings indicate that most primary pupils face difficulties in comprehending unfamiliar culture embedded in many English language lessons. It is believed that the outcomes of this study could shed some light to educators in reducing illiteracy rate as well as to be aware of the impact of CEFR towards LINUS. It is hoped that the findings could facilitate various stakeholders in designing materials for the teaching and learning of English language for primary school students in the future.
\end{abstract}




\section{Keywords}

Remedial Intervention Program, LINUS, Literasi Bahasa Inggeris (LBI), CEFR, Reading and Writing

\section{Introduction}

The Malaysian Education Blueprint (MEB) 2013-2025, which has been developed by the government, attempts to transform the education system in Malaysia. The transformation is vital to meet the current and future demands both locally and globally. Shan et al. (2016) have listed several aspirations in which every student is expected to have knowledge, thinking skills, leadership skills, bilingual proficiency, ethics and spirituality and national identity aligned with the national education philosophy. In accordance to that, pupils need to develop proficiency especially in reading and writing skills. Reading skills is very essential in upgrading the students' English proficiency since reading involves the process of decoding words in order to derive meaning (Floyd et al., 2007; Mohamad et al. 2015). Writing on the other hand, involves the reverse-encoding process. Both skills namely reading and writing are important in the aspect of language learning. The pupils need to be constantly reminded that continual development of their language proficiency is a necessary requirement as it contributes to the success in the development of literacy. Due to this reason, the Malaysian government feels that there is a need for educational transformation as education plays a significant role in the development of a country (Shan et al., 2016; Yamat et al., 2014). The implementation of the MEB has also brought about additional impact on the English Language Education especially in primary school level such as the inclusion of English literacy in the Literacy and Numeracy Screening or LINUS programme. After a few years of the implementation of LINUS, in 2018, the government introduces Common European Framework of References (CEFR) in our English language education system. Our pupils' proficiency level is being graded using CEFR descriptors in order to ensure that our students' grades are well recognized at international level. Besides the assessment descriptors, the CEFR textbook is also used for Year 1 and Year 2 pupils. Due to this current change, it is important for studies to be conducted to identify the effects of CEFR towards LINUS programme in our local context. Therefore, this study was embarked, with the aim to identify the effects of CEFR towards LINUS pupils' achievements.

The researchers provide more detailed information on what, why and how LINUS and CEFR programmes are implemented in Malaysia in the following sections.

\subsection{LINUS}

The Literacy and Numeracy Screening or LINUS is a remedial intervention 
program which was introduced in 2010 which aims at enhancing the rate of literacy among primary school learners in English, Bahasa Melayu and Mathematics. This program refers to a series of literacy tests which was executed twice a year namely in March and August. The questions were provided by the Ministry of Education. All identified lower primary pupils, regardless of their academic ability will go through the screening test to identify learning problems faced by them. The objectives of this program are to ensure that all primary school pupils should master basic literacy skills after three years of schooling (Sani \& Idris, 2013; Kadir, 2011). Teachers will determine the students' competency in both languages, English and Bahasa Melayu, and numeracy (Mathematics) using a standard test instrument. Eventually, children who are incompetent in the test will be categorized as LINUS students and treated in a special class namely LINUS Remedial Class. Shamsuri (2014) added that the objectives of the early intervention programme are to improve the quality of teaching and learning in English and also to increase the effectiveness of teaching and learning in remedial English classes (The New Straits Times, $21^{\text {st }}$ Sept). Students are tested based on the twelve constructs which emphasized on phonics, phonemes blending, segmenting, using language at word level, phrases, sentences and finally to write simple sentences. Constructs refer to the yardstick that is used to measure a set of predetermined skills needed for the pupils to pass the screening. These sets of skills were introduced to the pupils as early as their preschool years. The constructs are as follows (see Table 1).

\subsection{CEFR}

The key to our English education road map is the alignment of Malaysia's English Language Education System with CEFR; an international standard which focuses on producing learners who can communicate and interact in any language,

Table 1. Twelve LINUS constructs.

\begin{tabular}{cl}
\hline Constructs & \multicolumn{1}{c}{ Predetermined skills } \\
Construct 1 & Able to identify and distinguish shapes of the letters of the alphabet. \\
Construct 2 & Able to associate sounds with the letters of the alphabet. \\
Construct 3 & Able to blend phonemes into recognizable words. \\
Construct 4 & Able to segment words into phonemes. \\
Construct 5 & Able to understand and use the language at word level. \\
Construct 6 & Able to participate in daily conversations using appropriate phrases. \\
Construct 7 & Able to understand and use the language at phrase level in linear texts. \\
Construct 8 & Able to understand and use the language at phrase level in non-linear texts. \\
Construct 9 & Able to read and understand sentences with guidance. \\
Construct 10 & Able to understand and use the language at sentence level in non-linear texts. \\
Construct 11 & Able to understand and use the language at sentence level in linear texts. \\
Construct 12 & Able to construct sentences with guidance.
\end{tabular}


in this instance, English. Another significant key element of the educational reformation is to embrace the CEFR levels as the main structure for curriculum development, selection of learning materials and measuring the learning outcomes. CEFR was developed by the Council of Europe in the year 2001 and provides a general framework which specifies the important aspect that every language learners need to learn so as to enable them to use a foreign language effectively in practice. The CEFR provides a basis for language syllabuses, curriculum guidelines, examinations as well as textbooks not only across Europe but worldwide. It describes in a comprehensive way what language learners have to learn to do in order to use a language for communication and what knowledge and skills they have to develop to be able to act effectively (Yamat et al., 2014). CEFR also defines the proficiency levels that allow learners' progress to be measured at each stage of learning and on a life-long basis" (Council of Europe, 2001: p. 1). It also seems to be very useful in creating communicative and functional goals for learners to use with language.

CEFR can be regarded as an assessment model to measure foreign language proficiency or ability among the users which could be useful for varieties of languages and not strictly for English. However, in this study, the researchers only focus on the English language as this is the Malaysians' second language. English language is taught at least 6 hours per week at primary schools. There were six levels of language proficiency outlined in CEFR in relation to the five skills (listening, reading, spoken interaction, spoken production and writing) on a scale beginning with A1, and progressing through A2, B1, B2, C1 and finally, C2. Proficiency of each level is explained through these descriptors mentioned below (see Table 2).

These CEFR levels can be applied not only across schools and higher education institutions but also in businesses. The CEFR table above shows the scores ranging from 180 to 230 are for Proficient users of English which are C1 and C2. The scores ranging from 140 to 179 are for independent users of English, B1 and B2 and lastly scores ranging from 100 to 139 are for Basic users of English (A1 and A2) where pupils who obtained below 99 were required to study at a Pre A1. A person with a C2 level is recognized as a person who is able to reach a mastery use of English language.A person with an A1 level refers to a user who has a basic ability to use English language.

Therefore, in accordance to that, the launch of the English Language Education Roadmap for Malaysia 2015-2025 (Don et al., 2015) has progressively aligned with the MEB to serve as a guidance for English language teachers to ensure that students will be able to achieve proficiency levels equivalent to international standard which is the Common European Framework of References or CEFR. Another important element in the MEB is to boost the level of education in the country so as to be at par with international standard. In order to heighten the quality of LINUS 2.0 program, there is a suggestion to integrate CEFR into the LINUS 2.0 English language literacy program. As Duibhir and 
Table 2. CEFR Descriptors.

\begin{tabular}{|c|c|c|}
\hline USER & LEVELS & DESCRIPTORS \\
\hline $\mathrm{A}$ & $\begin{array}{c}\text { A1 } \\
\text { Beginner }\end{array}$ & $\begin{array}{l}\text { Can understand and use familiar everyday expressions and very basic phrases } \\
\text { aimed at the satisfaction of needs of a concrete type. Can introduce him/herself } \\
\text { and others and can ask and answer questions about personal details such as where } \\
\text { he/she lives, people he/she knows and things he/she has. Can interact in a simple } \\
\text { way provided the other person talks slowly and clearly and is prepared to help. }\end{array}$ \\
\hline $\begin{array}{c}\text { English } \\
\text { Basic User }\end{array}$ & $\begin{array}{l}\text { A2 } \\
\text { Elementary } \\
\text { English }\end{array}$ & $\begin{array}{l}\text { Can understand sentences and frequently used expressions related to areas of } \\
\text { most immediate relevance (e.g. very basic personal and family information, } \\
\text { shopping, local geography, employment). Can communicate in simple and } \\
\text { routine tasks requiring a simple and direct exchange of information on familiar } \\
\text { and routine matters. Can describe in simple terms aspects of his/her } \\
\text { background, immediate environment and matters in areas of immediate need. }\end{array}$ \\
\hline $\begin{array}{c}\text { B } \\
\text { English }\end{array}$ & $\begin{array}{l}\text { B1 } \\
\text { Intermediate } \\
\text { English }\end{array}$ & $\begin{array}{l}\text { Can understand the main points of clear standard input on familiar matters } \\
\text { regularly encountered in work, school, leisure, etc. Can deal with most situations } \\
\text { likely to arise whilst travelling in an area where the language is spoken. Can } \\
\text { produce simple connected text on topics which are familiar or of personal } \\
\text { interest. Can describe experiences and events, dreams, hopes \& ambitions } \\
\text { and briefly give reasons and explanations for opinions and plans. }\end{array}$ \\
\hline $\begin{array}{c}\text { Independent } \\
\text { User }\end{array}$ & $\begin{array}{c}\text { B2 } \\
\text { Upper-Intermediate } \\
\text { English }\end{array}$ & $\begin{array}{l}\text { Can understand the main ideas of complex text on both concrete and abstract } \\
\text { topics, including technical discussions in his/her field of specialisation. Can } \\
\text { interact with a degree of fluency and spontaneity that makes regular interaction } \\
\text { with native speakers quite possible without strain for either party. Can produce } \\
\text { clear, detailed text on a wide range of subjects and explain a viewpoint } \\
\text { on a topical issue giving the advantages and disadvantages of various options. }\end{array}$ \\
\hline $\begin{array}{c}\text { C } \\
\text { Proficient } \\
\text { English User }\end{array}$ & $\begin{array}{l}\text { C1 } \\
\text { Advanced } \\
\text { English }\end{array}$ & $\begin{array}{l}\text { Can understand a wide range of demanding, longer texts, and recognise implicit } \\
\text { meaning. Can express him/herself fluently and spontaneously without much } \\
\text { obvious searching for expressions. Can use language flexibly and effectively for } \\
\text { social, academic and professional purposes. Can produce clear, well-structured, } \\
\text { detailed text on complex subjects, showing controlled use of } \\
\text { organisational patterns, connectors and cohesive devices. } \\
\text { Can understand with ease virtually everything heard or read. Can } \\
\text { summarise information from different spoken and written sources, } \\
\text { reconstructing arguments and accounts in a coherent presentation. Can } \\
\text { express him/herself spontaneously, very fluently and precisely, } \\
\text { differentiating finer shades of meaning even in more complex situations. }\end{array}$ \\
\hline
\end{tabular}

Cummins (2012) suggested, adapting CEFR in an early literacy program provides a solid structure upon which a language learning pathway could be mapped. This is because learners could see how they build up their language skills and this "structure map" somehow establishes a concrete foundation for them in learning third or fourth languages later on (Duibhir \& Cummins, 2012).

\subsection{LINUS and CEFR}

The main objective of LINUS is to ensure that once the pupils have successfully 
completed their lower primary, they are expected to reach basic literacy and numeracy skills, which will be useful for their learning progress in future. At the same time, LINUS 2.0 is seen to have an addition of English language literacy skill, which is shared between both LINUS 2.0 assessment and CEFR. Thus, integrating both assessments will allow teachers and policymakers to assess these pupils' English language usage and literacy more effectively. However, only the first three levels of CEFR descriptors will be used in integrating CEFR into LINUS 2.0 which are A1, A2 and B1. This is because LINUS 2.0 are those low proficiency learners who are still developing their literacy skills in using English language and they might progress at quite a slow pace.

The plan for educational transformation is highlighted in the 2013-2025 Education Development Plan (Pelan Pembangunan Pendidikan, 2012) which indicates the initiative to align the Malay language as well as English language curriculum and assessment along the Common European Framework of Reference for Languages (CEFR); that is by applying CEFR scales as yardsticks to measure the language skills the pupils' hold (Yamat et al., 2014). The idea was that Malaysian students were expected to achieve the "operational" proficiency level defined by the CEFR as the linguistic competency required for full participation in professional and academic life.

Thus, the Ministry of Education has taken the decision of involving CEFR in language education, in order to measure students' language abilities against globally recognized levels. This proposed framework is seen to be able to support the language syllabuses and curriculum guidelines, the design of teaching and learning materials, as well as the assessment of foreign language proficiency. The former Deputy Education Minister of Malaysia, Datuk P. Kamalanathan, stated that all pre-schoolers, Year One and Two pupils, and Form One and Two students in Malaysia will begin their studies with the CEFR curriculum in 2018 (Chin \& Rajaendram, 2017). They will use the imported Cambridge University Press CEFR aligned English textbooks namely Superminds and Pulse 2 in schools. However, the introduction of CEFR in the curriculum bring about furore among teachers nationwide especially level 1 primary school English language teachers due to the perception among teachers of the "interference" on the implementations of LINUS 2.0 programme.

For that reason, this study was embarked to identify the impact of CEFR towards the achievement of Year 2 LINUS students as well as to find out the differences of Year 2 LINUS students' achievement after the implementation of CEFR. In order to achieve the purpose of this study, the following research questions were addressed:

1) Does CEFR help in improving Year 2 LINUS students' achievement?

2) Is there any differences in the result of LINUS screening test for Year 2 LINUS students after the implementation of CEFR?

It is hoped that findings from this study could be used to inform policy makers as well as facilitate language educators in designing materials for the teaching 
and learning of English language for primary school students in the future.

\section{Literature Review}

Although CEFR is newly-introduced in Malaysian school context, several studies in and outside Malaysia have been carried out by several researchers. In a research by Ramiaida et al. (2017), the findings shows variations in teachers' views towards the students' performance in English language proficiency courses which may not necessarily fit into the CEFR standards targeted for university learners. The areas of concern is on reading where a low percentage of teachers regard their students as able to understand main ideas of complex texts; and writing skill, while a very limited number of teachers feel that their students could produce clear and detailed texts. The result of this study acts as preliminary data for further research on the link between English language course content and CEFR standards, as well as the targeted aim of English proficiency level for university students.

A similar related study was conducted in Vietnam by Nguyen (2017) which evaluate the effectiveness of CEFR-V throughout the implementation of Vietnam's National Foreign Language 2020 or NFL 2020. The project was initiated in 2008 with the aim of enhancing foreign language teaching and learning. The findings indicate that the establishment of CEFR-V is needed to serve as a guideline for measuring and assessing language proficiency. This is further supported by another local study from Nguyen (2015) who investigated the standardized educational policy through a case study in a Vietnamese University. Findings from the study yielded positive outcome in which it can be seen that participants perceived more possible benefits than possible problems in CEFR-V. He also argues that the adoption of the CEFR can be considered as a "quick-fix" solution in enhancing the quality of English language education in Vietnam. Since the CEFR is widely employed in Europe and beyond, it is considered an ideal standard to adopt in Vietnam (Nguyen, 2015).

Maxwell (2015) reported that Thailand schools across the country have begun the process of aligning their English language teaching with the Common European Framework of Reference (CEFR) for languages (Asian Correspondent, $7^{\text {th }}$ April). This alignment is seen as a positive step towards raising the standards of English in Thailand. The Thai Ministry of Education has set the following English language proficiency targets for students in Thailand where by the end of Prathom 6 (Grade 6) students should have reached A1 proficiency, Mathayom 3 (Grade 9) students should have reached A2 proficiency and Mathayom 6 (Grade 12) students should have reached B1 proficiency. The targets for Grade 6 and Grade 9 are certainly within the reach of schools that emphasise English language learning, but the Grade 12 target of B1 proficiency is seen as ambitious. It is also been reported that although a large number of Thai teachers took the internationally recognized Oxford Placement Test in 2014 however they were not able to reach the intended proficiency. This is derived from another study con- 
ducted by Franz \& Teo (2017) in South Thailand which showed that many Thailand English teachers do not reach the proficiency level of B2. A number of English teachers have been getting some first-hand experience of the Common European Framework as part of an initiative to assess the ability of all English language teachers in Government schools and it appears that the implementation of CEFR assessment somehow did not meet the anticipated result. With Thailand still struggling under a reputation of poor levels of English proficiency, it is essential that some progress is made to rectify this situation.

Another study was carried out by Zheng, Zhang, \& Yan (2016) on the practice of CEFR in China. They found out that CEFR serve no purposes in enhancing the Chinese English language proficiency. Even though CEFR has been translated into Chinese language and was published for the purpose of English lesson, however the framework was not favorable even among language educators in the university. It is learned that CEFR assessment has no influence towards the teaching and learning of writing among Chinese English universities. However, through a series of workshops conducted among teachers, this group of people seemed to show their interest to try CEFR in their writing activity through assessments in class. These teachers too perceived CEFR as more rational and scientific.

A study on the influence of CEFR on English language education in Japan conducted by Fennely (2016) showed that CEFR has been making significant impact on the Japanese education system in recent years. However, the influences were seen to be different to those in Europe due to the Geo-political situation. The pressure to learn a foreign language other than English in Japan is very weak and the government does little to promote bilingualism. Teachers' understanding related to CEFR is also lacking. It is noted that using CEFR can-do statement can increase Japanese students' self-awareness of language use as well as increased autonomous learning. Nagai and O'Dwyer (2011) stated that in recent years, the CEFR Can-Do descriptors are strongly impacting school language education and Japan Ministry of Education directives. A survey conducted by Negishi and Tono (2014) showed that eighty percent of Japanese English language learners fall within CEFR "A" level and that there are very few who are at level "C". It was decided that the present CEFR levels were not sufficient to represent the level differentiation of language learners in Japan.

A local study by Ong et al. (2015) had suggested an integration between CEFR and LINUS 2.0 program which focused on English language literacy. This proposition is to heighten the quality of the LINUS 2.0 program where CEFR will be integrated and adapted into LINUS 2.0 English language literacy program. However, it was merely a proposal where no pilot test or project were carried out to prove the effectiveness. Since LINUS 2.0 has an addition of training English language literacy skill, which is shared between both CEFR and LINUS 2.0, thus integrating such assessments will allow test setters to assess students' English language usage and literacy more effectively. Only first three levels will be used 
which are A1, A2 and B1 because these are low proficiency learners.

Another local study was conducted by Tatiana and Gopal (2017). They had found out that CEFR is expected to play a vital role in the restructuring process in Malaysia's English Language education system for the coming decade. CEFR has been the framework of references which aims to boost the level of students' proficiency in Malaysia. Analysis of the responses from the participants in this study indicated that English language still remain to be difficult to master, due to speaking environment, proficiency of the teachers and other factors. However, the government has taken numerous measures to improve this situation.Just like any other new systems, lots of time were needed to start up the CEFR in order to provide positive opportunities for English learners. Thus, it is hoped that these measures will give positive impacts towards all pupils in Malaysia.

This study was embarked to reduce the literature gap as evidenced above. Thus far, there is very limited studies on the effects of CEFR towards LINUS programme pupils and teachers in Malaysia. It is hoped that the findings of this study could provide some insights to policy makers in Malaysia so that some measures could be taken to further improve the new English language education system.

\section{Methodology}

\subsection{Research Design}

The research design for this study was a mixed method approach. The quantitative part was carried out among the pupils by utilizing two different screening tests which comprises of questions ranging from vocabulary, reading and writing skills. The data of this study were taken from the results of second screening test in 2017 and first screening test in 2018. These tests were the screening assessment designed to identify the low proficiency pupils or LINUS pupils. The data derived from the screening tests were recorded online by the class teacher in the Ministry of Education's LINUS NKRA website. Besides the results of the screening test, the researchers also used the semi-structured interviews as the research instrument. The transcriptions of the interview recordings from the LINUS pupils and their English teachers were analysed. Purposive sampling criteria were used in selecting the teachers to be interviewed. They were chosen as they teach English and their direct involvement with the two programs.

\subsection{Population of the Study}

This research was conducted in a rural school in the district of Langkawi, Kedah. The sample population of this study are three classes of year 2 low proficiency pupils who faced difficulty in reading and writing. These pupils enrolled in remedial class or LINUS. The duration of this study was 14 days where it was carried out according to the schedule of the screening tests in all classes. The time used for the tests was as advised by the class teachers. The school is in the suburban area of Langkawi, Kedah where most pupils have low proficiency level in 
English due to lack of exposure towards the language. However, the pupils were expected to possess at least the basic knowledge of English as they have learnt the language since kindergarten. Moreover, English is taught for 10 periods which made up of 5 hours lesson per week.

All pupils involved in this study were given a set of screening tests. In answering the screening tests, they need to complete several English language questions within the time allocated ( 2 weeks). The questions were set by the Ministry of Education according to 12 different constructs laid out in the LINUS program. These sets of questions comprised of vocabulary, writing and reading tests. The data collected through the screening tests were analysed using simple figures and percentage and the data were put into tables.

Five teacher participants were selected for the semi-structured interviews. The selected teachers had given their consent to be interviewed. The interview questions were developed on the basis of the initial results of the analysis of the screening tests. The purpose of the interview was to elicit more information that the tests failed to provide. The interview questions were given to the experts for validation purposes. These experts have more than 10 years teaching experience in teaching English. In order to secure confidentiality, pseudonyms were used to replace the participants' names. Data from the interviews were transcribed in verbatim. The transcriptions were returned to the teachers so they could further check its content. They gave feedback if there are corrections need to be made on the transcriptions.

\subsection{Data Analysis}

Data analysis have been made by comparing the data taken from the second screening results of LINUS in 2017 with the data from the first screening result of LINUS in early 2018. The data from the study were analyzed and presented in Table 3. Table 2 shows the percentage of the second screening results of LINUS in 2017 and first screening results of LINUS in 2018.

\section{Findings}

Table 3 shows 32 out of 35 pupils from 2 Cemerlang passed the second screening

Table 3. Second screening 2017 year 2 LBI and first screening 2018 year 2 LBI result.

\begin{tabular}{|c|c|c|c|c|c|}
\hline \multirow{2}{*}{ Classes } & \multicolumn{2}{|c|}{$\begin{array}{c}\text { Second Screening } 2017 \\
\text { Year } 2 \text { LBI result }\end{array}$} & \multicolumn{2}{|c|}{$\begin{array}{l}\text { First Screening } 2018 \text { Year } 2 \\
\text { LBI result }\end{array}$} & \multirow{2}{*}{$\begin{array}{l}\text { Difference } \\
\quad \text { in } \%\end{array}$} \\
\hline & $\begin{array}{c}\text { Total no } \\
\text { of } \\
\text { students }\end{array}$ & $\begin{array}{c}\text { Total } \\
\text { Pass (\%) }\end{array}$ & $\begin{array}{l}\text { Total no of } \\
\text { students }\end{array}$ & $\begin{array}{c}\text { Total } \\
\text { Pass }(\%)\end{array}$ & \\
\hline $\begin{array}{c}2 \\
\text { CEMERLANG }\end{array}$ & 35 & $32(91.42 \%)$ & 39 & $36(92.30 \%)$ & 0.88 \\
\hline 2 PINTAR & 33 & $10(30.30 \%)$ & 36 & $12(33.33 \%)$ & 3.03 \\
\hline 2 INTELEK & 25 & $6(24.00 \%)$ & 28 & $5(17.86 \%)$ & -6.14 \\
\hline TOTAL & 93 & $48(51.61 \%)$ & 103 & $53(51.45 \%)$ & -0.16 \\
\hline
\end{tabular}


test in 2017 with $91.42 \%$ while 36 out of 39 pupils passed the first screening test for 2018 with $92.30 \%$. There is $0.88 \%$ difference in which the result seems to improve compared to the previous year.

However, in year 2 Pintar, only 10 pupils out of 33 passed in their second screening test for 2017 with $30.30 \%$ while 12 out of 36 pupils passed their first screening test in the year 2018 with $33.33 \%$. There is 3.03\% difference in both years which shows a progress in the test results.

Nevertheless, the second screening test in 2017 for 2 Intelek showed that 6 out of 25 pupils which made up $24 \%$ passed the test and only 5 out of 28 pupils passed the second screening test in 2018 with $17.86 \%$. There is a reduction of percentage of pupils passed in the latest screening test in the year 2018.

In general, the findings from Table 3 indicate a decrease in percentage of year 2 LINUS pupils' achievement in screening test results. There were 48 out of 93 pupils passed in 2017 with $51.61 \%$ whilst in 2018, only 53 out of 103 pupils passed the screening test which makes up of $51.45 \%$ reduction. Based on the comparison of the two screening results, it could be concluded that the total percentage of year 2 pupils passing the LBI LINUS screening test had decreased by 0.16 percent in 2018 compared to the result in 2017 .

\section{Discussion}

The data analysed earlier show a decrease number of year 2 pupils passing the LBI LINUS screening tests between the second screening in 2017 and first screening in 2018. Several factors influencing the results had been identified and were discussed in this section.

\subsection{Mismatch between Content and Curriculum}

The usage of Superminds textbook among these LINUS pupils were seen as irrelevant due to the mismatch between the content and curriculum taught in class and the questions given in the screening tests itself. One of the teachers, Faridah, stated that "we need to teach certain topics in class but they doesn't come out in LINUS". She further added that "my students cannot answer LINUS questions because what they learn in class and what's in the screening test is different'. The content in this imported textbook which were expected to yield positive results among low proficiency pupils were not related to local culture and surroundings. It also had been acknowledged that several words existed in the textbook were unfamiliar among these pupils. Another teacher identified that "the words in Superminds textbook are different from what we learn in Malaysia. For example the word 'rubber', I have been teaching my students 'eraser' since before". This claim is supported by another teacher, Londt, "the use of 'bike' instead of 'bicycle' and the most obvious is the contraction of' is' and 'am'. My students have difficulty in pronouncing the contraction 's and ' $m$ '. These teacher respondents viewed that the "English" way of setting in the textbook were seen as alien to both teachers and pupils thus created problems in the 
classroom. The concern raised by the teachers is that although the teaching contents of the LBI 2.0 programme are the same as those included in the standard curriculum or KSSR for the English subject, there is still a disparity between the contents taught in the programme and those in the curriculum (textbook). One of the teacher indicated that "the items for screening test might be similar to those included in KSSR, but now we use CEFR as our main resources, not KSSR anymore". This situation has created problems among the pupils where they were not able to cope with two different topics within the same session of learning. In other words, teachers need to teach unrelated topics to the pupils in the textbook and other topics in the module for the screening purposes.

\subsection{Lack of Basic Literacy Skills}

One of the aims of the Ministry of Education, Malaysia (MoE) is to eradicate illiteracy among young learners in school. The priority to combat this problem is high because it has been reported that pupils who dropped out of schools have difficulties in coping with the syllabus due to the lack of basic literacy skills (Economic Planning Unit, 2010). Most pupils who were affected by this problem came from a non-positive family background in which making them to not having good view of themselves. Studies have shown that children raised in poverty are less likely to have their crucial needs met than their more affluent peers and as a result, are subjected to some grave consequences. Deficits in these areas inhibit the production of new brain cells, alter the path of maturation, and rework the healthy neural circuitry in children's brains, thereby undermining emotional and social development and predisposing them to emotional dysfunction (Gunnar et al., 2009; Miller et al., 2006). Social dysfunction may hinder students' ability to work well in cooperative groups which leads their exclusion by group members. Jensen (2009) stated that, "This exclusion and the accompanying decrease in collaboration and exchange of information exacerbate at-risk students' already shaky academic performance and behaviour". Thus, the LINUS LBI 2.0 program can also be regarded as a rehabilitation program which is designed to ensure that pupils will be able to achieve a solid foundation of basic skills in the early three years of schooling besides to instil good value of themselves. As the teacher indicated, "many LINUS students were able to perform well when they were in Year 4 with the help of this program". Consequently, these pupils are able to apply the knowledge they get from the program when they move to primary level 2. Therefore, the ultimate goal of LBI 2.0 which is to detect the problem and restore the weakness at an earlier stage can be achieved so as to reduce the number of pupils being left behind in mastering the overall learning.

\subsection{Poor Learning Ability among Pupils}

Poor learning ability among pupils refers to pupils with some difficulties in the process of acquiring knowledge. Some pupils have learning difficulties but they do not have a certificate that informs that they are students with special educa- 
tion needs. Without the card, they are not entitled to be placed in a special education class. Therefore, these pupils must sit for the screening test. One of the teachers, Suzy, stated that, "dyslexic and learning problem students do not have to go through the screening tests since they are regarded as OKU (Orang Kurang Upaya), this includes students with physical disabilities. But they need to own certified card to prove that they are really $O K U^{p}$. Teachers have to give utmost attention to these pupils because many of them are unable to get hold of most subjects learnt in school especially languages and Mathematics. These students are categorized as low achievers who needed guidance in learning. One of the respondents stated that, "I don't know what is wrong with these kids. I have given my all energy to help them in learning but to no avaip". This is supported by another English teacher which specified that, "English is one of the most difficult language to learn, so it is not a surprise if these low achievers cannot get the hang of it".

Low achievers pupils possess low learning ability to grasp essential knowledge resulted in them to poorly perform in examinations. So, in order to stream them, they are usually placed in the last ranked class. Some of them cannot even read and understand the exam questions and write the answers properly, which make them unable to complete the test. According to the teachers involved, "these pupils are easily distracted during the learning process in class. They like to watch people walking outside rather than listening to what we teach in class. I almost give up with my students because of their behaviour". Nile (2006) pointed out that there is a weakness among students in the main stages of language skills due to the delay in the mastery of reading and writing skills, as well as weaknesses in the skills of writing the alphabet and calligraphy. The consequences of this situation are that it will also affect their achievement in Primary School Achievement Test (Ujian Penilaian Sekolah Rendah-UPSR). These pupils are likely to learn English for the sake of passing in examination without really understand the rules of the language itself. Though CEFR is implemented to enhance students' language skills, but the awareness towards the importance of the language is still low making the possibilities to fail is high.

\subsection{Nonexistence of Specialised LINUS Teacher Assistant}

The nonexistence of specialised LINUS teacher assistant in helping English teachers to run the program is also another issue raised by teachers in which they felt that it was unfair that they had to bear the cost on their own. According to Hadzir et al. (2016), there is a need to have more remedial teachers for English language to prevent teachers to be under pressure due to extra workload. By having sufficient number of teachers, assessments can be carried out in a more structured manner and teachers' psychological aspects can be taken care of. This is further added that during the intervention for the Malay language literacy and numeracy programme, the identified pupils will be assigned to specific remedial classrooms carried out by the specialised teacher assistant however, as for the 
LINUS LBI, the pupils who were identified for the LINUS programme were not being separated from their peers in the mainstream class. Thus, the teachers felt that teaching these weak pupils effectively was a daunting task. One of the teacher respondents stated that "I had difficulty in conducting the screening test because everyone is there... I mean, I need to supervise the screening test and at the same time, I need to make sure that other students were doing work given. I cannot really focus on conducting the test with the pupils because sometimes things got really chaotic. It would be great to have LINUS LBI special remedial class just like what we have for Bahasa Melayu". Another teacher supported by claiming that "I have a lot of pupils in my class, and to check their answers and attend to their need individually are quite hard and tiring. It was really hard to juggle between conducting the test and teaching the lesson especially with LINUS pupils".

Peng (2015) in her study about the implementation of LINUS also found that many of the selected LINUS teachers lacked the expertise of psycholinguistic knowledge (mentally and linguistic capabilities) and did not undergo appropriate training to acquire those knowledge. She further stated that LINUS teachers need to have the expertise to determine students' readiness, as well as sufficient knowledge on the guidance to be delivered to LINUS students. In addition, it is important for LINUS teachers to obtain psycholinguistic teaching methods that emphasize mental capacity and language mastery. The teaching method has a profound impact on LINUS pupils' reading and writing skills. Thus, the Ministry of Education needs to make a point that the LINUS teachers should be given adequate training and courses especially in the field of psycholinguistics. Azrina, one of the teacher responded that "The idea of having these screening tests are good, but the government should put more effort and carry out further research in improving the programme. Teachers with appropriate expertise and experiences were in dire need to make this successful. It's really important to have someone with good psycholinguistic knowledge to help these students to improve in the language and to achieve the learning target. If not, all the efforts will go straight into the drain. The least we can do is to give a helping hand but an expert would really make a difference".

\section{Conclusion}

On the whole, findings from the study illustrate a decrease in percentage of the screening test results for year 2 LINUS pupils' achievement. A sum of 48 out of 93 pupils passed in 2017 which brings $51.61 \%$ whilst only 53 out of 103 pupils passed the screening test in 2018 , which makes up of $51.45 \%$ reduction. Thus, built on the comparison from the two screening results, it could be concluded that total percentage of year 2 pupils passing the LBI LINUS screening test had decreased by 0.16 percent in 2018 compared to the result in 2017 .

These findings could also facilitate various stakeholders in designing learning materials for effective classroom practices of English language in the future. For 
example, the content of the newly imported "Superminds" textbook from Cambridge University Press can be considered as unfamiliar to some, and taxing to another due to the culture and environment constraints. However, the "Superminds" textbook supplied by the ministry can still be used but after an appropriate review and evaluation especially in the usage of the terms and cultural settings. Henceforth, thorough planning and strategies need to be considered while implementing early literacy assessment as the results of assessment are useful to be used in helping pupils' early literacy learning and providing vital information for educators in using the most effective instruction in language classroom. LINUS 2.0 and CEFR are two vigorous programs which would bring significant results if executed as expected. Yet, more research should be conducted to provide valuable suggestions to improve the quality of the LINUS 2.0 early literacy program and the implementation of CEFR descriptor in schools throughout Malaysia. The CEFR can provide a useful tool in planning the curriculum development, teaching and learning activities, and assessment at all levels of English language education to ensure the success of English language teaching and learning in universities to suit the current English education transformation (Darmi et al., 2017). Teachers and stakeholders need to take into account pupils' learning ability as well as the suitability of unfamiliar language and cultural setting when designing the intervention program. Teachers still need time to familiarize themselves with the textbook and various courses were needed to before it is executed in schools.

On the other hand, the development of literacy skills is extremely important especially among young learners. Early literacy skills have a clear and consistently strong relationship with later conventional literacy skills, such as decoding, oral reading, fluency, reading comprehension, writing and spelling (National Institute for Literacy, n.d.). Good foundation in literacy skills will benefit children's learning progress and as well as provide them with a better future. Undoubtedly, more studies and programs are being conducted worldwide to raise awareness of early literacy skills development. Henceforth, thorough planning and strategies need to be considered while implementing early literacy assessment as the results of assessment are useful to be used in helping children's early literacy learning and providing vital information for educators in using the most effective instruction in language classroom. LINUS 2.0 and CEFR are two vigorous programs which would bring significant results if executed as expected. However, more research should be conducted to provide valuable suggestions to improve the quality of the LINUS 2.0 early literacy program and the implementation of CEFR descriptor in schools throughout Malaysia.

Generally, the implementation of integration of CEFR descriptor in LINUS screening test might be helpful in a way which CEFR provides a standard yardstick assessing language proficiency in which most pupils were likely to achieve. According to Piccardo et al. (2017), CEFR is a language policy document intended to define levels of language proficiency in terms of real-world practical 
ability. However, the execution of this integration ought to be thorough and tangible and takes into account the reality of Malaysian education landscape. LINUS screening test results must really portray the situation of low proficiency pupils in the school, not just the ideal number of pupils who achieved the target as required by the district officers. The execution of integrating CEFR in LINUS screening assessment too should be reconsidered to see whether it is really measuring the corresponding target or just another screening evaluation that was according to the previous KSSR module. Malaysia is advancing towards improving the quality of teaching and learning practice progressively. As cited by Tatiana and Gopal (2017), Malaysian Government takes leaps to provide the positive opportunities for English learners. The important aspect is the shift Malaysia English Language Education System towards the CEFR for Languages.This contribution will affect English learning in a positive manner. It is hoped that the outcomes of this study could shed some light to educators to be aware of the impact of CEFR towards the achievement of pupils from LINUS programme.

\section{Conflicts of Interest}

The authors declare no conflicts of interest regarding the publication of this paper.

\section{References}

(2012). Pelan Pembangunan Pendidikan Malaysia 2013-2025. Putrajaya: Kementerian Pendidikan Malaysia.

Chin, C., \& Rajaendram, R. (2017). The Star Online. https://www.thestar.com.my/news/nation/2017/10/05/only-imported-english-textbook s-from-next-year-move-part-of-reform-to-ensure-international-proficien/

Council of Europe (2001). Common European Framework of Reference for Languages. Language Policy Unit, Strasbourg. http://www.coe.int/lang-CEFR

Darmi, R., Saad, N. S. M., Abdullah, N., Puteh-Behak, F., Zakaria, Z. A., \& Adnan, J. N. I. (2017). Teachers' Views on Students' Performance in English Language Proficiency Courses via CEFR Descriptors. International E-Journal of Advances in Education, 3, 363-370. https://doi.org/10.18768/ijaedu.336688

Don, Z. M., Abdullah, M. H., Abdullah, A. C., Lee, B. H., Kaur, K., Pillai, J., \& Hooi, M. Y. (2015). English Language Education Reform in Malaysia: The Roadmap 2015-2025. Putrajaya: Ministry of Education.

Duibhir, P. O., \& Cummins, J. (2012). Towards and Integrated Language Curriculum in Early Childhood and Primary Education (3 - 12 Years): Commissioned Research Report. Dublin: NCCA.

Economic Planning Unit (2010). Tenth Malaysia Plan 2011-2015: Chapter 5. Putrajaya: Prime Ministers's Department.

Fennely, M. G. (2016). The Influence of CEFR on English Language Education in Japan. Bulletin of Shikoku University, (A)46, 109-122.

Floyd, R. G., Keith, T. Z., Taub, G. E., \& McGrew, K. (2007). Cattell-Horn-Carroll Cognitive Abilities and Their Effects on Reading Decoding Skills: g Has Indirect Effects, More Specific Abilities Have Direct Effects. School Psychology Quarterly, 22, 200-233. 
https://doi.org/10.1037/1045-3830.22.2.200

Franz, J., \& Teo, A. (2017). “A2 Is Normal”-Thai Secondary School English Teachers Encounters with the CEFR. RELC Journal. https://doi.org/10.1177/0033688217738816

Gunnar, M. R., Frenn, K., Wewerka, S. S., \& Van Ryzin, M. J. (2009). Moderate versus Severe Early Life Stress. Association with Stress Reactivity and Regulations in 10-12 Year-Old Children. Psychoenuro Endocrinology, 34, 62-75. https://doi.org/10.1016/j.psyneuen.2008.08.013

Hadzir, N., Alias, A. M., Kamaruzaman, A. L., \& Mohd Yusof, H. M. (2016). Teachers' Perception On Literacy, Numeracy and Screening (LINUS 2.0) Assessment Features Based On Year 1 Students' Performance. Research Journal of English Language and Literature (RJELAL), 4, 40-47.

Jensen, E. (2009). Teaching with Poverty in Mind: What Being Poor Does to Kids' Brains and What Schools Can Do about It. Alexandria, VA: Association for Supervision and Curriculum Development.

Kadir, A. Z. (2011). Sudut pandang Muhyiddin Yassin: Isu, kontroversi, pandangan serta harapan, sebuah wawancara. Kuala Lumpur: Institut Terjemahan Negara Malaysia Berhad.

Maxwell, D. (2015). Thai Schools Adopt European Framework to Boost English Language Proficiency.

https://asiancorrespondent.com/2015/04/thai-schools-adopt-european-framework-to-b oost-english-language-proficiency/\#S8jycJrM7ISATTB1.99

Miller, A. L., Seifer, R., Stroud, L., Sheinkopf, S. J., \& Dickstein, S. (2006). Biobehavioral Indices of Emotion Regulation Relate to School Attitudes, Motivation, and Behavior Problems in a Low-Income Preschool Sample. Annals of the New York Academy of Sciences, 1094, 325-329. https://doi.org/10.1196/annals.1376.043

Mohamad, M., Hamdan, N. A., Shaharuddin, S., \& Khalid, F. (2015). Hypermedia Reading Strategies of TESL Undergraduate Students in Malaysia. Turkish Online Journal of Educational Technology, 2015, 301-310.

Nagai, N., \& O'Dweyer, F. (2011). The Actual and Potential Impacts of the CEFR on Language Education in Japan. Synergies Europe, 6, 141-152.

National Institute for Literacy (n.d.). Early Beginnings: Early Literacy Knowledge and Instruction. Washington DC: Author. https://lincs.ed.gov/publications/pdf/NELPEarlyBeginnings09.pdf

Negishi, M., \& Tono, Y. (2014). An Update on the CEFR-J Project and Its Impact on English Language Education in Japan. ALTE Paris.

http://events.cambridgeenglish.org/alte-2014/docs/presentations/alte2014-masashi-neg ishi.pdf

Nguyen, N. H. (2015). Vietnam's National Foreign Languages Project 2020: Challenges, Opportunities, and Solutions (pp. 62-64). English for ASEAN Integration: Policies and Practices in the Region.

Nguyen, N. T. (2017). EFL Teachers' Perceptions towards the Use of CEFR-V. European Journal of English Language Teaching, 2, 74-86.

Nile, A. (2006). Linguistic Weakness, Diagnosis and Treatment. Dar Alwafa, 90-93.

Ong, L. Y. E., Roselan, F. I., Anwardeen, N. H., Hazirah, F., \& Mustapa, M. (2015). Suitability of the Literacy and Numeracy Screening (LINUS) 2.0 Programme in Assessing Children's Early Literacy. The Malaysian Online Journal of Educational Science, 3, 36-44.

Peng, C. (2015). Pelaksanaan Program Literasi dan Numerasi (LINUS) di Sekolah Ren- 
dah. Jurnal Pendidikan Bahasa Melayu, 5, 1-11.

Piccardo, E., North, B., \& Maldina, E. (2017). QualiCEFR: A Quality Assurance Template to Achieve Innovation and Refoem in Language Education through CEFR Implementation. In Learning and Assessment: Making the Connections (pp. 94-103). Bologna: Association of Language Testers in Europe.

Sani, N., \& Idris, A. R. (2013). Implementation of Linus Programme Based on the Model of Van Meter and Van Horn. The Malaysian Online Journal of Educational Science, 1, 25-36.

Shan, P. L. M., Yunus, M. M., \& Mohamad, M. (2016) Its Effects on English Language Teaching in Malaysia. Asian EFL Journal, 4.

Tatiana, S., \& Gopal, S. (2017). A Survey of English Language Teaching in Higher Institutions of Learning in Kuala Lumpur Malaysia.

Yamat, H., Umar, N. F. M., \& Mahmood, M. I. (2014). Upholding the Malay Language and Strengthening the English Language Policy: An Education Reform. International Education Studies, 7, 197-205. https://doi.org/10.5539/ies.v7n13p197

Zheng, Y., Zhang, Y., \& Yan, Y. (2016). Investigating the Practice of the Common European Framework of Reference for Languages (CEFR) outside Europe: A Case Study on the Assessment of Writing in English in China. 